\title{
Domestic Tourism as a Vehicle for Tolerance and Peace Building: Lessons from World Heritage Sites in the Amhara Regional State, Ethiopia
}

\author{
Yechale Mehiret Geremew \\ Department of Tourism Management, University of Gondar, Gondar, Ethiopia
}

\begin{abstract}
The major purpose of this study was to examine whether and under what conditions that domestic tourism can help for tolerance and peace building in the Amhara world heritage Sites, Ethiopia. To achieve this objective, quantitative and qualitative case study method, and purposive and stratified sampling techniques were employed for questionnaire, focus group discussion and interview data gathering instruments. Quantitative data was hand-coded into SPSS (version 19) and analyzed using both descriptive and inferential statistics. Therefore, tourism experts and domestic tourists were participated and the collected data was analyzed by descriptive statistics, independent t-test, one way ANOVA and post hoc. The quality of quantitative data from questionnaire survey was checked by using reliability (Cronbach's alpha) and validity (factor analysis) test. The qualitative data was collected from experts and domestic tourists and analyzed through interpretative and descriptive account of the data. To assure the reliability of qualitative data all interviews and group discussions were recorded and registered word for word throughout the courses of interviews and focus group discussions. The interpretation of qualitative data was a thematic descriptive approach that utilizes a theme summary data and unattributed quotes to illustrate dominant issues in respondents' own words. The major findings of the study indicate that an increment of academic qualification and experience of travelling to different parts of the country can help to understand the role of domestic tourism for tolerance and peace building. However, the Amhara regional state government should not viewed domestic tourism as some form of vector of economic domination, but is very much seen to be an instrument of tolerance and peace building; a sustainable economic, environmental and social tool for development were some of the recommendations given.
\end{abstract}

Keywords: Domestic Tourism, Tolerance and Peace Building, Amhara Regional State and Ethiopia

\section{Background: Relevance and the State of Knowledge}

Despite great strides in global communication technologies, the need for peoples to talk and understand one another is ever pressing. Although the nature of tourism involves only a transient encounter between peoples, at its most basic level it is a vitally important means by which peoples can interact, exchange stories, ideas and objects, and create a shared feeling of human belonging. As throughout history, travel and human interaction is the way we come to know and understand one another socially and culturally (UNESCO, 2006). In a global society which travels more than ever before, tourism represents an important instrument of exchange and dialogue. In the words of the International Cultural Tourism Charter adopted by ICOMOS in 1999: "Domestic and international tourism continues to be among the foremost vehicles for tolerance and peace building, providing a personal experience, not only of that which has survived from the past, but of the contemporary life and society of others."

Dialogue amongst civilizations is a central pillar of UNESCO ${ }^{\text {es }}$ work, enshrined in its constitution as a means to build "peace in the minds of men", and is a key focus for its cultural programmes. The adage that, travel broadens the mind ${ }^{\text {ee }}$ lies closely with the notion of dialogue as a means to gain knowledge of other societies and cultures. While not the sole means to achieving peace and security, dialogue is a key part of the process of creating conditions for mutual understanding and awareness of culture(s) and cultural difference, and of preventing cultural prejudice. In the words of Kofi Annan in announcing the United Nations Year of
Dialogue Amongst Civilizations in 2001: "I see dialogue as a chance for people of different cultures and traditions to get to know each other better, whether they live on opposite sides of the world or on the same street."In the long term, no one culture can successfully exist without contact with other cultures and other cultural influences, drawn from diverse histories and the complexities of constant global change. Therefore, domestic tourism has a critical role to play in facilitating and shaping tolerance and peace building (Viard, 2000).

On the most basic levels, a nation such as Ethiopia is not benefiting to the extent it could from domestic tourism given the rich cultural and heritage resources it possesses. Clearly the reasons for this are complex, but its present level of domestic tourist share would seem, with the right support and development frameworks, to present considerable opportunity. It must be remembered that the overall national flow of tourists is decidedly asymmetrical with a significant percentage of tourists travelling from relatively urban (developed) to rural (developing) regions, reflecting long term historical imbalances in economic and political power, and also in terms of rights and freedoms. In the near future this essentially mono-polar flow of tourists from the nation's richest to some of the poorer regions is unlikely to change significantly. Within this context it is important that tourism is not viewed as some form of vector of economic domination, but is very much seen to be an instrument of development; a sustainable economic and social tool for developing nations (MoCT, 2009).

Therefore, domestic tourism as a vehicle for tolerance and peace building is the choice of the study. The first reason is; Ethiopia is a country of more than 80 nations, nationalities

\section{Volume 4 Issue 11, November 2015}




\section{International Journal of Science and Research (IJSR) \\ ISSN (Online): 2319-7064}

Index Copernicus Value (2013): 6.14 | Impact Factor (2014): 5.611

and peoples. Much of these nations, nationalities and peoples have their own distinct culture, history, language and way of life, they have also a history which they share in common. Although, the Ethiopian Nations, Nationalities and Peoples were the kind of proud people who had all the way managed to successfully, defend their sovereignty and their country against any foreign aggressors, there were also black spots in their long-standing existence (HF, 2014). In addition to this, the presence of international tourists has become an important feature in everyday life of many Ethiopians, in both rural and urban areas (MoCT, 2009). However, the problem is when the rationale for tourism development has been discussed within the country; it is often conceived in macroeconomic terms: generation of foreign exchange, government revenue and employment. These benefit the whole of Ethiopians, but it ignores the social and political elements of tourism sustainability (WB, 2003).

The second problem is that Ethiopian international tourismes social footprint is particularly troubling in light of its speedy growth and predictions for continued expansion. It has detrimental social impacts to historical sites and cultural heritage if it is not planned and controlled. However, the tourism industry must be the more concerned than any other sector in the nation's political stability and the cultural preservation since the survival is rely upon the existence of these resources (EPA, undated). Thirdly, even if the number of tourists visiting the country has increased every year, Ethiopia still receives only a small fraction of the visitors even to east Africa (UNWTO, 2001). Those tourists, who do visit, with the exception of trekkers, stay for short durations (MoCT, 2009). Although, the contribution of these short stayed tourists to the economy cannot be dismissed, the host and guest generate unfavorable effect on each other. They have an erosion of local customs, an increase in beggars and theft of antiques and cultural property (Saker, 2006).

Finally, the understanding level of tourism experts on domestic tourism is not clear for the smooth running of the industry and above all studies regarding the socio cultural and political regulation on Ethiopian domestic tourism industry are few. Even the studies that have been made are sketchy and isolated; they shed very little light on the subject matter. In order to promote the development of domestic tourism that prevents or minimizes cultural degradation, more in-depth studies are needed for the smooth running of the tourism industry with other sectors. Therefore, the purpose of this research is to study domestic tourism as a vehicle for tolerance and peace building in Amhara Regional State world heritage sites (Gondar, Debark and Lalibela).

\section{Methods of the Study}

The methodological approach for this study was described as a case study of Amhara world heritage sites within the qualitative and quantitative domains. In the course of the fieldwork, the study was relied on both primary and secondary sources of data. Primary data was including indepth open-ended and semi-structured interviews; this permits the researcher to probe to unearth respondents ${ }^{\text {ee }}$ over all perception of domestic tourism development, document consultation and questionnaires with the target population of the study. Formal and informal discussions also were conducted with different associations, experts and government officials. Secondary data was include archival research from books, proclamations, regulations, journals, magazines, proceedings, pamphlets, manuals, bulletins, newspapers, reports, articles, internet materials and individual writing exercises related to the study. Therefore, descriptive research design sourced through questionnaire, interview, focus group discussion and document consultation was employed.

The Amhara regional state tourism bureau experts, different tourism related associations and domestic tourists, which are directly involving in the industry and working at Gondar, Debark and Lalibela were the target of the study. A random sample of all legally operating tourism offices and associations in the case study area was drawn from Amhara regional state tourism bureau database. So, offices and associations in the case study area have been taken as a sample frame for the qualitative data collection instrument. Therefore, Yamane (1967) sample size determination formula with the assumption of a $95 \%$ confidence interval, and $5 \%$ precision level (Where, $\mathbf{n}$ is sample size, $\mathbf{N}$ is population size, and $\alpha$ is level of precision (0.05) was employed to determine the number of participant population for questionnaire survey. Whereas, data saturation was used to determine the number of interviewees.

$$
n=\frac{N}{1+N(\alpha) 2}
$$

Accordingly, as per the data collected from each culture and tourism office (Gondar, Debark and Lalibela) are visited averagely by $325,132, \& 243$ domestic tourists per week and the researchers collected the data within a week time frame and took these as a population size and calculated as follow:

$\mathrm{n}=700 / 1+700(0.05)^{2}$

$\mathrm{n}=255$

However, the number of participants to each destination (stratum) was distributed using Kothari (2004) sample distribution formula.

$$
n 1=\left(\frac{N 1}{N}\right) n
$$

Where, „N1 ${ }^{\text {ee }}$ the total number of population in each destination, ,n1 $1^{\text {ee }}$ the number of participants in each stratum, , $\mathrm{N}^{\mathrm{ee}}$ the total number of population in all destinations, and , $\mathrm{n}^{\text {ee }}$ the total number of sample participants. Therefore, according to the formula $118,48 \& 89$ samples were taken randomly from Gondar, Debark and Lalibela tourist destinations respectively. However, the sampling procedure of the interviewees was purposively selected, which helped the researchers to exclude uninterested respondents, consider variations in education level and experience of respondents to the subject of the study.

\section{Results of the Study}

Based on the sampling technique and procedure described, totally two hundred fifty five (255) copies of questionnaires were distributed to the respondents of the study and only two hundred thirty two (232) were properly completed and valid (91\%). Accordingly, the first part of the questionnaires was distributed to one hundred eighteen (118) those sampled from Gondar domestic tourists, out of these questionnaires, only one hundred seven (107) were filled in and valid

\section{Volume 4 Issue 11, November 2015}




\section{International Journal of Science and Research (IJSR) \\ ISSN (Online): 2319-7064 \\ Index Copernicus Value (2013): 6.14 | Impact Factor (2014): 5.611}

$(90.68 \%)$. The second questionnaires were distributed to forty eight (48) Debark domestic tourists, out of these questionnaires, forty five (45) were filled in and valid $(93.75 \%)$. The third questionnaire was distributed to eighty nine (89) from Lalibela domestic tourists, out of these eighty (80) were filled it and returned $(89.89 \%)$. The items in the questionnaire were grouped into two parts. The first part contains items related to respondents ${ }^{\text {ee }}$ characteristics about their level of education and travel experience, and the second part comprises of variables related to domestic tourism and tolerance and peace building . Furthermore, unstructured interview was held with five senior experts and three domestic tourists at each stratum, a total of twenty four respondents, based on the data saturation principle. This is important to obtain data with regard to issues that required more clarification. In doing so, the characteristics of respondents, academic qualification and years of travelling experience is based on the responses to the background data in the first part of the questionnaire obtained from two hundred thirty two domestic tourists.

At this time, two key forces are driving the level of understanding of domestic tourists ${ }^{\text {ee }}$ on domestic tourisme $\mathrm{s}$ role for tolerance and peace building. First, tourists are increasingly aware of the impacts of international tourism development on local environments and communities, and second, the drive towards corporate citizenship has forced responsibility and accountability to the top of the businesses agenda. There is increasing recognition of the significant shift away from the predominance of the traditional international tourism towards more experiential domestic tourism. Travel is increasingly about experiences, fulfillment and rejuvenation, rather than about places and things. In addition to a shift in demand for the types of tourism products being demanded, tourists themselves are becoming vigilant consumers, and are increasingly concerned with the impact of their actions on the environment and local communities. The extent to which consumer's awareness of social and environmental issues actually impacts on tourism purchasing patterns is still open for debate (King, 2002). However, one school of thought argues that sustainability issues understanding is increasingly affecting actual buying patterns and behaviors of tourists (Tearfund, 2001 and 2002). In research undertaken for the international ecotourism society, consumers indicated that they were willing to pay more for ethical business practices, were willing to contribute to community projects (Chafe, 2004).

Therefore, in order to reveal the average level of understanding of respondents, independent t-test for academic qualification groups and one way ANOVA analysis for years of experience groups, Post hoc comparison to determine which mean differ significantly after a significant $\mathrm{F}$ - ratio has been found in the ANOVA summary and descriptive statistics to show the average understanding level of respondents were conducted.

Table 1: Level of Understanding in Academic Qualification of Respondents on the Role of Domestic Tourism for Tolerance and Peace Building

\begin{tabular}{|c|c|c|c|c|c|c|}
\hline Variables & Academic Qualification & N & Mean & SD & t-value & Sig. \\
\hline Tolerance \& & Diploma \& Below & 31 & 27.1613 & 5.79135 & -3.111 & 0.003 \\
\cline { 2 - 6 } Peace Building & BA/BSc \& Above & 17 & 31.7059 & 2.11438 & & \\
\end{tabular}

Source: Data Compiled

As it can be seen from the t-test result of table one, there is a statistically significant difference between Diploma and below, and $\mathrm{BA} / \mathrm{BSc}$ and above respondents in their understanding level of domestic tourismes role on tolerance and peace building at $95 \%$ confidence interval with a value of $(\mathrm{t}(230)=-3.111, \mathrm{p}<0.05$ (2-tailed $))$. This indicates that the understanding level of $\mathrm{BA} / \mathrm{BSc}$ and above respondents on the role of domestic tourism as a tool for tolerance and peace building is better than Diploma and below holder respondents with mean value of 31.7059 and 27.1613 respectively. Therefore, an increase in academic qualification leads to a better understanding of respondents on the role of domestic tourism for tolerance and peace building.

Table 2: Level of Understanding in Travelling Year of Experience of Respondents on the Role of Domestic Tourism for Tolerance and Peace Building

\begin{tabular}{|c|c|c|c|c|c|c|}
\hline Variables & Source of Variation & Sum of Squares & Df & Mean Square & F & Sig. \\
\hline Tolerance \& Peace & Between Groups & 582.637 & 3 & 194.212 & \multirow{2}{*}{11.838} & \multirow{2}{*}{.000} \\
\cline { 2 - 6 } Building & Within Groups & 721.843 & 228 & 16.406 & & \\
\cline { 2 - 5 } & Total & 1304.479 & 231 & & & \\
\hline
\end{tabular}

Source: Data Compiled

As it is indicated in the ANOVA result of table two, there is statistically significant difference in the level of understanding on domestic tourism and tolerance and peace building issues among respondents who have below five years of travelling experience, between five and ten, eleven and fifteen, and those who have travelled above fifteen years as a domestic tourist. In the same way, it shows that there is a statistically significant difference of understanding on domestic tourism and tolerance and peace building issues among respondents of the four experience categories ( $\mathrm{F}$ (3, $228)=11.838, p<0.05)$. This also indicates that there is a difference in the understanding level of the groups on the issues and an increase in experience leads to a better understanding of domestic tourism as a tool for tolerance and peace building up to eleven to fifteen years of experience. But, this does not mean that there is significant difference between each category. Therefore, the understanding level of respondents on the role domestic 


\section{International Journal of Science and Research (IJSR) \\ ISSN (Online): 2319-7064}

Index Copernicus Value (2013): 6.14 | Impact Factor (2014): 5.611

tourism for tolerance and peace building is not equal or at least the understanding of one of the experience categories differs from the other three. The problem is how to determine which means differ significantly after a significant $\mathrm{F}$ - ratio has been found in the ANOVA summary. To determine this, post hoc comparison test method was used and the result shows that the respondents for under five years experience, in the four understanding variables, is different from five to ten, eleven to fifteen and above fifteen years of travelling experienced respondents with a mean of $9.45029,-13.07656$ and -12.67251 at 0.05 level of significance respectively. This means that there is a significant understanding difference among those respondents who have travelled under five years and other experienced respondents. However, there is no significant difference among the three categories of respondents who have traveled above five years of experience.

Consequently, the contribution of domestic tourism to tolerance and peace building is understood as a process that comprises an open and respectful exchange of views between individuals and groups with different ethnic, cultural, religious and linguistic backgrounds and heritage, on the basis of mutual understanding and respect. It requires the freedom and ability to express oneself, as well as the willingness and capacity to listen to the views of others. On the other round, domestic tourism contributes to political, social, cultural and economic integration and the cohesion of culturally diverse societies. It fosters equality, human dignity and a sense of common purpose. It aims to develop a deeper understanding of diverse world views and practices, to increase co-operation and participation (or the freedom to make choices), to allow personal growth and transformation, and to promote tolerance and respect for the other. Therefore, domestic tourism is a powerful instrument of mediation and reconciliation: through critical and constructive engagement across cultural fault-lines, it addresses real concerns about social fragmentation and insecurity while fostering integration and social cohesion. Freedom of choice, freedom of expression, equality, tolerance and mutual respect for human dignity are among the guiding principles in this context. Successful intercultural dialogue requires many of the attitudes fostered by a democratic culture - including open-mindedness, willingness to engage in dialogue and allow others to express their point, a capacity to resolve conflicts by peaceful means and recognition of the well-founded arguments of others. However, domestic tourism is not a cure for all evils and an answer to all questions, and one has to recognize that its scope can be limited. It is often pointed out, rightly, that domestic tourism with those who refuse travel is impossible, although this does not relieve open and democratic societies of their obligation to constantly offer opportunities for travelling. On the other hand, domestic tourism with those who are ready to take part in travelling but do not - or do not fully - share their values may be the starting point of a longer process of interaction, at the end of which an agreement on the significance and practical implementation of the values of human rights, democracy and the rule of law may very well be reached.

In fact, domestic tourism is the first form of tourism that was practiced and today it continues to account for the most part of this activity by far. In contrast to international tourists, domestic tourists know the destination, its language, its customs, its laws, its climate and its cultural context. Whether it is to rest, discover new things, meet others or to have a unique experience, everyone has a right to tourism; in short, there are not, there should not be, and there cannot be two categories of human beings, those who can be tourists and those who can only receive them. These two activities are, in fact, but two sides of the same human activity; both of them are noble and respectable and everyone is entitled to them.

Table 3: Contribution of Domestic Tourism to Tolerance and Peace Building

\begin{tabular}{|c|c|c|c|c|c|c|}
\hline \multirow[b]{2}{*}{ No } & \multirow[b]{2}{*}{ Items } & \multicolumn{4}{|c|}{ Frequencies } & \multirow{2}{*}{$\begin{array}{l}\text { Standard } \\
\text { Deviation }\end{array}$} \\
\hline & & $\begin{array}{l}\text { Disagree } \\
(\%)\end{array}$ & $\begin{array}{c}\text { Neither Disagree } \\
\text { nor Agree (\%) }\end{array}$ & Agree (\%) & Mean & \\
\hline 1 & $\begin{array}{c}\text { Freedom of choice, freedom of expression, equality, } \\
\text { tolerance and mutual respect for human dignity are among } \\
\text { the guiding principles of domestic tourism }\end{array}$ & 0.0 & 0.0 & 100 & 4.6 & 0.40 \\
\hline 2 & $\begin{array}{c}\begin{array}{c}\text { Domestic tourism helps for peaceful relationships between } \\
\text { the guest and host }\end{array} \\
\end{array}$ & 0.0 & 10.3 & 89.8 & 4.35 & 0.7 \\
\hline 3 & Domestic tourism helps to practice justice & 15.3 & 0.0 & 84.7 & 3.8 & 1.0 \\
\hline 4 & $\begin{array}{l}\text { Domestic tourism contributes to culture of peace among the } \\
\text { tourists }\end{array}$ & 22.9 & 8.6 & 68.6 & 3.3 & 1.3 \\
\hline 5 & $\begin{array}{l}\text { Domestic tourism is a vital force for peace and a factor of } \\
\text { friendship and understanding among the people of the nation }\end{array}$ & 17.2 & 4.3 & 78.6 & 3.4 & 1.1 \\
\hline 6 & $\begin{array}{l}\text { Every domestic tourist is potentially an ambassador for } \\
\text { peace }\end{array}$ & 42.9 & 14.3 & 42.9 & 3.0 & 1.7 \\
\hline 7 & $\begin{array}{c}\text { Domestic tourism is vital force for peace and international } \\
\text { understanding }\end{array}$ & 22.9 & 0.0 & 77.2 & 3.14 & 1.1 \\
\hline
\end{tabular}

Source: Compiled Data

As table three in the first row depicts that $232(100 \%)$ of the respondents agreed that freedom of choice, freedom of expression, equality, tolerance and mutual respect for human dignity are among the guiding practices of domestic tourism. Equally, in row two of the table shows that 208 (89.8\%) of respondents agreed that domestic tourism facilitate for peaceful relationships between the guest and host but 24 $(10.2 \%)$ of them were indifferent about the issue. Similarly, in row three of the table shows that 197 (84.7\%) of the respondents agreed that domestic tourism assist to practice 


\section{International Journal of Science and Research (IJSR) \\ ISSN (Online): 2319-7064}

Index Copernicus Value (2013): 6.14 | Impact Factor (2014): 5.611

justice in the place where it is visited. On the contrary, 35 $(15.3 \%)$ of respondents disagreed that domestic tourism assist to practice justice. To sum up, from the whole data gathered, domestic tourism can serve as a means of tolerance and peace building practices in the study area with a mean value of 3.60 .

\section{Conclusion and Recommendations}

\subsection{Conclusion}

The travel and tourism industry - the golden child of global economic sectors - has been credited for many things. The attraction of travelers from across the globe to onees home nation has proven a powerful force for global diplomacy, strengthening understanding of cultures, ideologies and attitudes. The idea of traveling across the world, across borders and across time zones is exciting, enticing, inspiring, informing, educating, and very sexy. It affords the traveler the opportunity to explore, learn, and grow while away and to brag once back. However, a number of destinations managed to offset their international inbound tourism losses during the period of recessionary decline by focusing on their domestic tourism offering. With clarity and confidence, strategic plans put the lens on home-growth traveler potential, encouraging nationals to explore their own countries, taking a much-needed break within their own borders. Despite domestic tourism, globally, is much greater than international tourism in terms of volume of visitors, it is the invisible portion of the total tourism activities. According to some studies, domestic tourism flow worldwide may soon be ten times larger than international tourism flows. Despite this promising value, many governments and researchers tend to overlook this market at the expense of international tourism because of the default thinking that domestic travelers simply do not offer the same degree of benefit to the local market. They pay in local currency, are sensitive to local pricing (and tourist-targeted price increases), are less awed by local attractions, and are locals themselves, really, so do not offer the same visitor excitement as foreigners.

The findings suggest that (t-test, one way ANOVA \& post hoc) an increasing in academic qualification and those who have less than five years of travelling experience and above leads to an increment of understanding level of the respondents on domestic tourism 's contribution to tolerance and peace building. Even if the understanding level of respondents varies in academic qualification and year of experience, statistically the understanding mean values of the variable is 3.68 that shows agreement, the average domestic tourist respondents have the knowledge on the elements of domestic tourism and tolerance and peace building . Lastly, if domestic tourism develops in a meaningful, sustainable and complementary way to international tourism, it will offer destinations an exceptional platform for year-round tourism economy growth and development. And, as importantly, domestic tourism creates a destination that stands proud as a place for both the people of the world, and those of the destination, to explore and enjoy as their own. Therefore, the finding of this research is parallel to the previous studies that domestic tourism can serve as a vehicle for tolerance and peace building in the study area.

\subsection{Recommendations}

There is no magic formula and much depends on the national and regional context of domestic tourism. The development of domestic tourism should not be regarded as antagonistic or alternative to international tourism; these two forms of tourism are different to be sure, but they complement each other closely and one should not be neglected in favor of the other. Therefore, the following recommendations are given based on the results of the study.

- In order to turn the peace-through-tourism discourse into practice in the Amhara National Regional State, more open dialogue is needed between policy makers and industry representatives on the one hand, and scholars on the other. It is only through more collaboration within the tourism sector - public and private; academic and industry - that domestic tourism can ever become a true peacebuilder, both within and outside tourism.

- The Amhara National Regional State (ANRS) should also be humble and stress that progress towards national peace cannot be an isolated tourism process; it is part of a larger social change that begins with recognizing that the fundamental social and political order needs to be transformed. Domestic tourism always functions as part of the wider economic and geopolitical systems from which it cannot be divorced. If we take the idea to build cultures of peace seriously, informed action is needed on multiple fronts. This includes addressing the issues of social injustice and other types of conflict within the industry itself.

- The Amhara National Regional State (ANRS) strategic plans should put the lens on home growth traveler potentials, domestic tourism.

- The Amhara Regional State Culture, Tourism and Parks Development Bureau and higher educational institutions should organized trainings, workshops or seminars on the contribution of domestic tourism for tolerance and peace building.

- The Amhara Regional State, Education Bureau should foster a culture of peace through education by revising the educational curricula to promote qualitative values, attitudes and behaviors of a culture of peace, including peaceful conflict resolution, dialogue, consensus-building, active non-violence and inclusion of tourism and related subjects at elementary level.

- The Amhara Regional State's Educational Institutions should organize and actively participate in tourism related clubs like ,know your country"e

- The Amhara Regional State should organize different national and regional events and evaluate its impact on time.

- The respective destination administrations should include the importance of domestic tourism for tolerance and peace building in their interpretations.

\section{References}

[1] Bryman, A., Becker, S. and Sempik, J. (2008). 'Quality criteria for quantitative, qualitative and mixed methods 


\section{International Journal of Science and Research (IJSR) \\ ISSN (Online): 2319-7064}

Index Copernicus Value (2013): 6.14 | Impact Factor (2014): 5.611

research $^{\text {ee }}$ (Revised edn.), Oxford: Oxford University Press.

[2] Chafe, Z. (2004). Consumer demand and operator support for socially and environmentally responsible tourism. CESD/TIES Working Paper No 104, Washington.

[3] De Vellis. (1991). Research methodology; techniques of data quality management

[4] Environmental Protection Authority (EPA). (Undated). Environmental Policy of Ethiopia. Resource Base and the need for a Policy. Addis Ababa, Ethiopia.

[5] House of Federation. (2014). Ethiopian Nations, Nationalities and Peoples Day Report. Addis Ababa.

[6] ICOMOS. (1999). $8^{\text {th }}$ Draft of the International Cultural Tourism Charter Managing Tourismat Places of Heritage Significance. ICOMOS International Scientific Committee on Cultural Tourism Secretariat, Burwood Victoria, Australia.

[7] Kathori. (2004). Research methodology; sampling methods and techniques

[8] King, J. (2002). Destination Marketing Organizations Connecting the experiences rather than promoting the place. Journal of Vacation Marketing, Vol. 8, No. 2.

[9] Ministry of Culture and Tourism. (2009). Tourism Statistics Bulletin (2006-2008). No. 9, Addis Ababa.

[10] Nunnally \& Bernstein. (1994). Making Sense of Factor Analysis: The Use of Factor Analysis for Instrument testing'

[11] Saker. (2006). Positioning Ethiopia as a Worldwide Tourism Destination: Focus on University of Gondar Chronicle, Vol. 6, No. 1, Gondar, University of Gondar Press.

[12] Tearfund. (2001). Guide to tourism: Don't forget your ethics! Tearfund, London.

[13]_. (2002). Worlds apart: A call to responsible global tourism. Tearfund, London.

[14] UNESCO. (2006). Tourism, culture and sustainable tourism. Document No. CLT/CPD/CAD-06/13

[15] United Nations World Tourism Organization (UNWTO). (2001). Voluntary Initiatives in Sustainable Tourism: Worldwide inventory and comparative analysis of 104 eco labels, awards, and selfcommitments. Madrid, Spain.

[16]Viard J. (2000). Court traité sur les vacances, les voyages et l'hospitalité des lieux. Aube, Paris.

[17] World Bank. (2003). Ethiopia, in Makeda's Footsteps: Towards a strategy for pro-poor Tourism Development. Report No. 38420-ET, p. 67.

[18] Yamane, T. (1976). Statistics, an Introductory Analysis, 2nd Ed. New York: Harper and Row. 